\title{
Las relaciones económicas entre Argentina y Venezuela durante las administraciones Kirchner-Chávez (2003-2008) Mariano Roark y Mariana Calvento
}

\author{
Mariano Roark es Licenciado en Relaciones \\ Internacionales (UNCPBA) y becario de la Comisión de \\ Investigaciones Científicas de la Provincia de Buenos \\ Aires, CEIPIL- UNCPBA. \\ E-mail: marianoroark@hotmail.com
}

Mariana Calvento es Licenciada en Relaciones Internacionales (UNCPBA) y becaria doctoral CONICET, CEIPIL- UNCPBA.

\section{resumen}

El artículo analiza las relaciones bilaterales entre Argentina y Venezuela durante el período 2003-2008 y sus antecedentes, centrándose principalmente en los aspectos económico-comerciales de la misma. Para ello, la investigación se desarrolla en dos planos. El primero, indaga sobre los antecedentes de dicha relación en el período previo, 1990-2003, tanto en sus aspectos comerciales como en relación con los acuerdos e instrumentos de vinculación que se establecieron entre ambos países.

En el segundo plano se avanza sobre la temática central del artículo, ahondando en las características de la relación comercial entre Argentina y Venezuela durante las presidencias de Néstor Kirchner y Hugo Chávez. Para ello, se detalla el acercamiento y cooperación entre los países durante esta etapa, así como también se profundiza sobre las particularidades de la relación comercial establecida.

A partir del análisis de estas dos etapas, se extraen las consideraciones preliminares acerca del relacionamiento argentino-venezolano de los últimos tiempos y las posibles oportunidades de vinculación comercial a futuro.

\section{palabras clave}

relaciones comerciales / economía internacional / acuerdos comerciales / Argentina / Venezuela

\section{summary}

The article analyzes the bilateral relation between Argentina and Venezuela during the period 2003-2008 and its antecedents, focusing in the economical and commercial aspects. Following that objective this investigation is developed in two points. The first one, deals about the antecedents of that international relation, in the previous historical moment, 1990-2003, rearding its trade aspects as well as the agreements and binding instruments established between both countries.

The second one talks about the central theme of the article, diving in the aspects of the business relationship between Argentina and Venezuela during Néstor Kirchner and Hugo Chávez presidencies. To reach it, the approach and cooperation between this countries during this moment, is highly detailed, so as the particularities of the commercial relation.

Based on the analysis of these two periods, preliminary considerations are extracted from the Argentina-Venezuela current relation and about future trade linking possibilities.

\section{keywords}

commercial relations / international economy / trade agreements / Argentina / Venezuela 


\section{Introducción}

El presente trabajo busca analizar las relaciones bilaterales entre Argentina y Venezuela durante el período 2003-2008, con el objetivo general de brindar una aproximación al proceso de acercamiento comercial desarrollado recientemente por dichos países, de modo de establecer un análisis general acerca de las oportunidades y desafíos que implica el estrechamiento de vínculos con el país caribeño.

En este sentido, es preciso destacar que el componente económico de la relación bilateral entre Argentina y Venezuela constituye uno de los aspectos más relegados en el análisis académico de la vinculación bilateral, en relación con el predominio de los estudios centrados en asuntos de tipo político-diplomáticos, pero actualmente se constituye en una variable interesante a indagar. A partir de mediados de 2003, como consecuencia de un proceso complejo, en el que se sucedieron simultáneamente transformaciones en la coyuntura económica internacional y en las circunstancias políticas y económicas domesticas se generó un marco bilateral favorable a un mayor estrechamiento de los vínculos económicos.

A partir de entonces, los flujos de bienes y capitales entre ambas economías no sólo experimentaron un incremento exponencial en términos cuantitativos, sino que, en el transcurso del período de gobierno de las administraciones KirchnerChávez, la composición misma de los intercambios bilaterales comenzó a mutar paulatinamente hacia un nuevo patrón de relacionamiento comercial, caracterizado por una mayor participación de productos elaborados y semi-elaborados.

Del mismo modo, durante el período 2003-2008, Argentina y Venezuela lograron instrumentar una serie de acuerdos bilaterales de significativa relevancia que apuntaron a profundizar el proceso de integración entre ambas economías. En este sentido, la suscripción del Tratado de Libre Comercio CAN ${ }^{1}-$ Mercosur $^{2}$ en 2003, en conjunto con el Convenio Integral de Cooperación, puesto en marcha a partir de 2004, incluyen una serie de medidas concretas en materia de preferencias arancelarias y cooperación técnica en sectores económicos y actividades productivas diversas, que han servido como marco normativo de las relaciones económico-comerciales entre ambos países, favoreciendo la intensificación de los intercambios bilaterales. De esta manera, el análisis del funcionamiento y la puesta en práctica de dichos instrumentos internacionales constituyen antecedentes inmediatos que permiten realizar una evaluación concreta del posible impacto del ingreso de Venezuela como miembro pleno del Mercosur, en vistas de la pronta conclusión del proceso iniciado en Julio de 2006 a través de la conclusión del Protocolo de Adhesión en la ciudad de Caracas.

En relación con el objetivo general del trabajo y para comprender el alcance y la importancia de las nuevas tendencias que se están gestando a nivel económicocomercial entre Argentina y Venezuela, la investigación se centra en la descripción y el análisis del desempeño histórico de dichos lazos a través de las dos etapas en que se dividen los últimos años de relación, 1990-2003 y 2003-2008.

Se parte de considerar que para estudiar las relaciones entre dos países es necesario contar con diversos elementos que permitan establecer una mayor compre- 
sión de su desempeño y vinculación en el plano internacional. Por ello, en este trabajo se considera que la política exterior de los países se establece en torno a variables internas y externas, y que principalmente la política exterior guarda relación con una estrategia nacional de desarrollo (Perina y Russell, 1988) y con el contexto internacional en el que se desempeña. Por tanto, la descripción de las relaciones bilaterales y su entendimiento realizados en este trabajo serán enmarcados sintéticamente en dichas variables internas y externas.

El artículo se estructura alrededor de tres secciones, para las que se retoman las dos etapas en que se desarrolla la relación económica bilateral de ArgentinaVenezuela en los últimos años. De esta manera, la primera sección trata, por un lado, sobre la dinámica de los vínculos comerciales y financieros durante la etapa 1990-2003. En la misma sección se desarrollan también los principales instrumentos internacionales que lograron concretarse durante el transcurso de esta primera etapa, haciendo especial hincapié en aquellos vinculados a temáticas afines.

La segunda sección abarca el estudio de las relaciones económicas bilaterales a partir del año 2003, en el contexto de un nuevo marco de cooperación política y profundización de los vínculos comerciales. Seguidamente, la sección se aboca al análisis sistemático de la composición de los intercambios comerciales entre Argentina y Venezuela y su evolución durante los últimos años.

Finalmente, el último apartado de consideraciones finales, brinda un balance preliminar del estado actual de las relaciones económicas entre ambas naciones, identificando los desafíos y oportunidades que de allí se desprenden para la economía argentina.

\section{Primera Sección}

\section{a. Comercio e inversión en la década del noventa}

Durante una primera etapa de las relaciones económicas entre Argentina y Venezuela, es decir, durante el período transcurrido entre 1990 y 2003, los rasgos centrales del intercambio de bienes y capitales entre ambos países se vincularon con el desarrollo de un comercio intermitente de baja intensidad y la existencia de una dinámica diferenciada respecto a los flujos financieros.

En el plano comercial, como puede observarse en el Gráfico $\mathrm{N}^{\circ} 1$, entre 1990 y 1999 Argentina y Venezuela mantuvieron un volumen de intercambios moderado aunque relativamente estable, con una fase de auge entre 1995 y 1998, cuando el valor de los intercambios se incrementó en un 52\%. La suma promedio de las transacciones efectuadas durante estos años alcanzó la cifra de 314 millones de dólares, con un saldo comercial de alrededor de 210 millones de la misma moneda, favorable a Argentina.

A pesar de esta significativa performance, durante el año de mayor expansión de las exportaciones argentinas a Venezuela (1995), el mercado caribeño significó apenas el 1,8\% del total de las ventas nacionales, ubicándose en el décimo segundo lugar entre los principales destinos.

Por el lado de las importaciones, es preciso destacar que Venezuela nunca ocupó un lugar destacado entre los países proveedores de Argentina y la década del no- 
venta no fue la excepción. El país caribeño tuvo una débil participación en el total de compras nacionales. Se ubicó en el lugar 41 en la lista de las principales fuentes de importación nacional y exhibió pisos históricos como el de 1990, cuando sólo se exportaron a nuestro país mercancías por un total de 8 millones de dólares.

Gráfico 1. Relaciones comerciales de Argentina con Venezuela, 1990- 1999

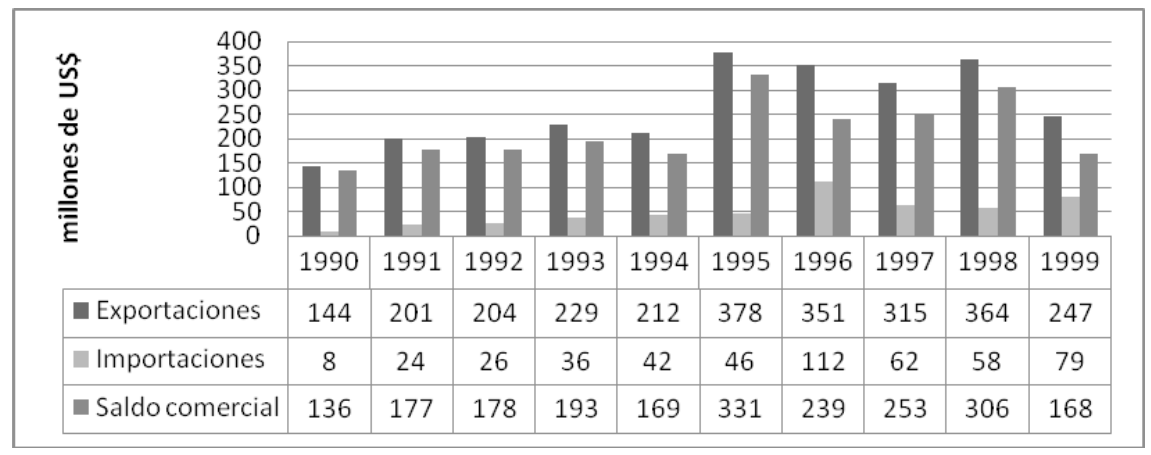

Fuente: Elaboración propia en base a datos de CEI (2009) y CEP (2008)

Hacia el final de la década, el ciclo comercial bilateral comenzó a transitar por una abrupta fase de declive. De acuerdo a datos del Centro de Economía Internacional (CEI), volcados en el Gráfico $\mathrm{N}^{\circ} 2$, la reducción del $45 \%$ en el volumen total de los intercambios, en 1999, dio inicio a una pendiente de contracción de los flujos bilaterales. Para 2003, las transacciones de bienes entre ambas economías descendieron a 129 millones dólares, menos de la mitad del monto registrado en 1998.

La razón fundamental de este encogimiento de los vínculos económicos radica en la confluencia de dos factores. Por el lado de Venezuela, la caída de los precios internacionales del crudo, que llegó a pisar la cifra histórica de 10 dólares el barril en $1998^{3}$, tuvo un impacto decisivo en el sector externo del país caribeño, que sufrió una disminución del $25 \%$ de sus exportaciones. En Argentina, el panorama era aún menos alentador. A principios del nuevo milenio comenzó a desatarse una de las crisis económicas más importantes de los últimos 50 años. Entre 1999 y 2002, todos los indicadores macroeconómicos y sociales se desplomaron y la actividad comercial experimentó una significativa desaceleración. Las importaciones pasaron de 31.377 millones de dólares en 1998 a 8.990 en 2002. Del mismo modo, teniendo en cuenta los totales de 1998 y 1999, las ventas nacionales al exterior, en un solo año se redujeron en más de 3.000 millones de dólares.

La dinámica en los flujos de inversiones entre ambas naciones experimentó un destino similar. Tuvo un moderado impacto a principios de la década del noventa, una fase de auge en la segunda mitad y sobre el comienzo del nuevo milenio comenzó a transitar el camino del declive. La diferencia que separa a estos dos aspectos de las relaciones económicas argentino-venezolanas, radica en la impor- 
tancia superlativa que representaron los flujos de capitales durante su período de plenitud. La relevancia de las inversiones nacionales en la economía venezolana durante los años noventa revistió tal magnitud que se convirtió en el eje principal de los vínculos materiales entre ambos Estados.

Gráfico 2. Intercambio comercial de Argentina con Venezuela, 1993-2003

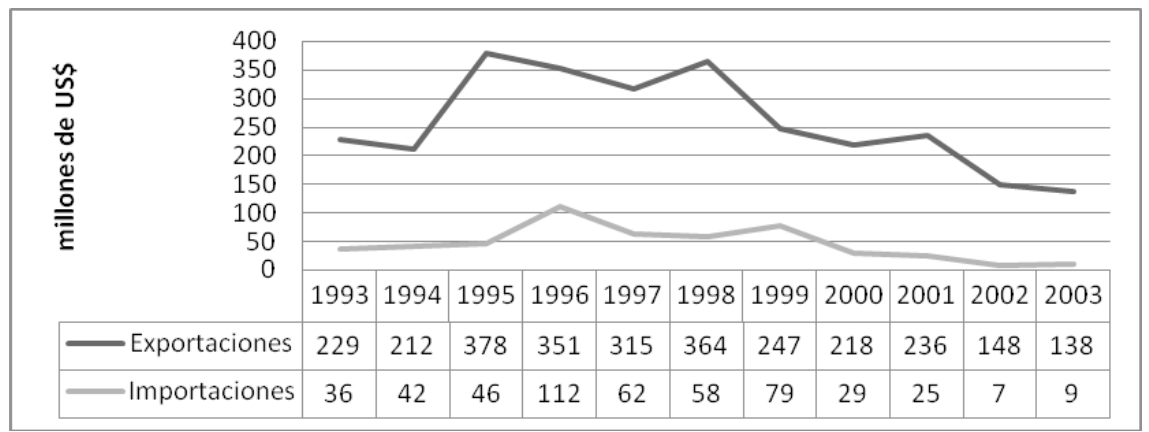

Fuente: Elaboración propia en base a datos de CEI (2009) y CEP (2008)

De acuerdo con datos del Centro de Estudios para la Producción (CEP), entre $1997^{4}$ y 2000, Venezuela se erigió como el segundo receptor latinoamericano de inversiones argentinas (después de Brasil), recibiendo el 17,7\% del total invertido a nivel internacional. Asimismo, debido a este notable incremento de los flujos financieros, Argentina se colocó en el segundo lugar de importancia como inversor extranjero en Venezuela, superando incluso a EE.UU. (Ver Cuadro $N^{o} 1$ ).

La dinámica altamente concentrada se constituyó en el común denominador durante este proceso de internacionalización de los capitales argentinos. Pocas compañías dominaron la mayor parte de los capitales invertidos y el destino sectorial de dichos flujos se redujo a un pequeño número de actividades económicas. Es así que, de acuerdo con la CEPAL, del total de los capitales argentinos colocados en Venezuela en 1997, tres empresas (Pérez-Companc, YPF y Techint) acumularon una participación de más del 80\% (Kosacoff, 1999: 8). Dentro de este procentaje, los rubros de exploración y explotación petrolera, el sector siderúrgico y la construcción constituyeron los principales destinos sectoriales, sumando, en conjunto, alrededor del 75\% del total entre 1990 y 1999 .

Otro rasgo particular de este proceso fue su carácter breve y efímero. A pesar de haber mostrado un ritmo frenético en sus inicios, a comienzos del nuevo milenio la intensidad en el movimiento de flujos de capital se desmoronó abruptamente a raíz de la delicada situación política y económica que atravesaban ambos países.

Por el lado de Argentina, el colapso económico-financiero de 2001 impuso serias restricciones al mercado nacional de capitales. El modelo económico implementado en este país a partir de la década del 90, y con antecedentes de la década del 70, había significado un cambio profundo en el patrón productivo, pasando de ser un modelo industrial sustitutivo de importaciones a uno que impulsaba políticas 
económicas de apertura comercial. Este modelo involucraba medidas relativas a la desregulación económica, privatización de empresas públicas y liberalización comercial y financiera, acompañadas por una moneda asociada a un patrón de tipo de cambio fijo denominado Plan de Convertibilidad. ${ }^{5}$ La liberalización y dependencia financiera implicó que la economía quedara expuesta a las interrupciones en los flujos internacionales de capital, provocando severas crisis fiscales y monetarias. En ese sentido, durante los noventa se produjeron diversas crisis internacionales, como la mencionada en el año 2001.

Cuadro 1. Distribución geográfica de las inversiones argentinas en el exterior

\begin{tabular}{|c|c|c|c|c|}
\hline \multirow{2}{*}{$\begin{array}{l}\text { Destino de } \\
\text { la actividad } \\
\text { IED }\end{array}$} & \multicolumn{2}{|c|}{$1990-1996$} & \multicolumn{2}{|c|}{$1997-2000$} \\
\hline & $\begin{array}{l}\text { Millo- } \\
\text { nes de } \\
\text { US\$ }\end{array}$ & $\begin{array}{l}\text { Por- } \\
\text { cen- } \\
\text { tajes }\end{array}$ & $\begin{array}{l}\text { Millo- } \\
\text { nes de } \\
\text { US\$ }\end{array}$ & $\begin{array}{l}\text { Por- } \\
\text { cen- } \\
\text { tajes }\end{array}$ \\
\hline Brasil & 655 & 16.7 & 2129 & 31.3 \\
\hline Venezuela & 329 & 8.4 & 1928 & 28.3 \\
\hline Bolivia & 180 & 4.6 & 1012 & 14.9 \\
\hline Estados Unidos & 1099 & 28.1 & 133 & 2.0 \\
\hline Indonesia & 861 & 22.0 & 333 & 4.9 \\
\hline Turkmenistán & 400 & 10.2 & 100 & 1.5 \\
\hline Chile & 0 & 0.0 & 450 & 6.6 \\
\hline Total & 3916 & 100.0 & 6808 & 100.0 \\
\hline
\end{tabular}

Fuente: Kosacoff (1999)

En el caso de Venezuela, las causas de la inestabilidad económica y política tienen su raíz en el agotamiento del modelo de desarrollo interno, producto de las debilidades estructurales de su sistema económico-productivo. Desde principios de la década del veinte, la explotación y comercialización masiva de los hidrocarburos se fue posicionando como el eje central de la economía nacional, desplazando rápidamente a la producción de bienes tradicionales como el café y el cacao, hasta constituirse en la mercancía de exportación nacional de mayor importancia (concentra más del $90 \%$ de las exportaciones en la actualidad) y en la principal fuente de ingresos fiscales para el Estado (históricamente, más del 50\% del total).

Ahora bien, este alto grado de especialización en las actividades petroleras vuelve a su economía profundamente dependiente de los movimientos cíclicos de los precios del petróleo y de las coyunturas económicas de los países industriales (principales mercados de destino de las exportaciones de petróleo). Durante las décadas del sesenta y setenta, en un contexto generalizado de expansión econó- 
mica internacional, los altos ingresos petroleros constituyeron la base para una expansión significativa del gasto público, lo que, sumado a la implementación de un modelo de sustitución de importaciones, generó un periodo histórico de prosperidad económica y social sin precedentes.

A fines de la década del ochenta, las circunstancias externas comenzaron a cambiar y el modelo económico empezó a mostrar sus flaquezas. Los precios internacionales del petróleo iniciaron una fase descendente ${ }^{7}$ que se extendió a lo largo de toda la década del noventa, llegando a un piso de 10 dólares el barril. Asimismo, las políticas de apertura comercial y recortes del gasto del Estado, iniciadas por Carlos Andrés Pérez (1989-1993) y continuadas por Rafael Caldera (1994-1999), eliminaron las palancas tradicionales de crecimiento interno. La crisis económi$\mathrm{ca}^{8}$ constituyó el denominador común de este periodo y la inestabilidad política resultó inevitable. ${ }^{9}$

El surgimiento de este nuevo marco tuvo un efecto inmediato sobre los flujos de capitales en Venezuela. En primer lugar, a causa de la disminución de los precios internacionales del petróleo, Venezuela se unió a la estrategia adoptada por la OPEP y decidió impulsar una reducción de la producción que favoreciera un alza de precios. Las empresas privadas nacionales y extranjeras comenzaron a ser afectadas por este recorte de producción y amenazaron con retirarse. En segundo lugar, se produjeron ciertas tensiones con multinacionales y capitales foráneos por la incertidumbre que generaba la popularidad de Hugo Chávez en las próximas elecciones presidenciales.

Como consecuencia, Venezuela dejó de ser un destino atractivo para los capitales foráneos. Entre 2001 y 2002, las inversiones argentinas en Venezuela sólo registraron 67 millones de dólares, contribuyendo con una participación irrisoria del $0,7 \%$ en el total invertido en la economía caribeña.

\section{b. Instrumentos internacionales}

Uno de los aspectos más destacables de las relaciones bilaterales argentino-venezolanas durante la década de 1990 se vincula con la configuración de un entramado de acuerdos y entendimientos de carácter comercial, que constituyeron el puntapié inicial de un proceso de integración económica que aún está en marcha.

Durante esta primera etapa, la construcción de una estructura legal para la relación de ambas economías se desarrolló básicamente en dos niveles: por un lado, dentro de un marco de negociaciones directas o bilaterales, y por otro, a través de los mecanismos regionales del Mercosur.

Ambos escenarios conformaban un espacio geográfico de extraordinaria importancia para la economía venezolana. Allí convivían su principal mercado de exportaciones a nivel regional (Brasil), y uno de los más importantes proveedores de inversiones extranjeras: la República Argentina.

De este modo, esta significativa relevancia dio sentido a la convicción de la diplomacia venezolana de lograr un entendimiento con las economías más australes de Sudamérica. Es así que, a principios de los años noventa, a nivel bilateral se lograron concluir una serie de tratados en materia de comercio e inversiones, 
que dieron un impulso significativo a los intercambios de bienes y capitales entre ambas naciones. El 28 de septiembre de 1990, los gobiernos de Argentina y Venezuela acordaron un Memorándum de Entendimiento para un Acuerdo Marco de Liberación Comercial. Dos años más tarde, en octubre de 1992, se suscribió el primer Acuerdo de Alcance Parcial de Complementación Económica (ACP-20), al que posteriormente se adhirieron 14 Protocolos Adicionales (el último en el año 2000). En la esfera financiera, ambos Estados concluyeron un Acuerdo para la Promoción y Protección Recíprocas de Inversiones a mediados de noviembre de 1993, que sirvió de base para el significativo impulso de los flujos de capitales durante la segunda mitad de los noventa.

En el plano regional, la victoria del histórico líder venezolano, Rafael Caldera, en los comicios presidenciales de 1994, marcó el inicio de una ofensiva política para lograr un entendimiento entre la Comunidad Andina y el Mercosur. El comercio interbloque se había vuelto clave ante la disminución de los precios internacionales de los hidrocarburos y la creciente crisis de la economía venezolana. Se respiraba un clima político enrarecido y convulsionado, y cada día se hacía más evidente la necesidad de diversificar las exportaciones en aras de obtener los ingresos de divisas que el petróleo ya no generaba. En este escenario, el objetivo de profundizar los vínculos económicos con aquellos países que constituían mercados potenciales para su producción no tradicional, se colocó al tope de la agenda de la política exterior.

Con el tiempo las iniciativas venezolanas tendrían sus frutos. Entre 1997 y 1998, en las ciudades de Montevideo y Lima, se concretaron tres reuniones cumbre entre representantes de la CAN y el Mercosur. Durante estos encuentros ambos grupos de naciones manifestaron el propósito de crear una zona de libre comercio sudamericana. A partir de entonces, se inició un largo proceso de avances y retrocesos entre ambos bloques regionales, que duró hasta mediados de 2003.

El primer paso concreto hacia ese objetivo tuvo lugar el 16 de abril de 1998, gracias a la suscripción de un Acuerdo Marco para la creación de una Zona de Libre Comercio entre la Comunidad Andina y el Mercosur, que establece las bases para la conformación de ese espacio ampliado. A través de este arreglo, se dispuso que las negociaciones se desarrollarían en dos etapas: en la primera, se trataría de alcanzar un Acuerdo de Preferencias Arancelarias Fijas sobre la base del patrimonio histórico y en la segunda un Acuerdo de Libre Comercio.

Con base a estos nuevos lineamientos fijados en el Acuerdo Marco, la Comunidad Andina y el Mercosur iniciaron, en junio de 1998, las negociaciones de un Acuerdo de Preferencias Arancelarias. La modalidad de negociación, que inicialmente fue de bloque a bloque (esquema 4+4) fue cambiada, a sugerencia de Brasil, por la de los andinos en su conjunto con cada uno de los países del Mercosur (4+1), manteniéndose sin embargo el objetivo final.

Como resultado de estas negociaciones, Colombia, Ecuador, Perú y Venezuela suscribieron con Brasil, el 12 de agosto de 1999, un Acuerdo de Alcance Parcial de Complementación Económica por medio del cual ambas partes establecieron márgenes de preferencia fijos, como un primer paso para la creación de una Zona 
de Libre Comercio entre la CAN y el Mercosur. Con igual objetivo, Argentina y la CAN negociaron un Acuerdo de Preferencias Arancelarias, que fue suscrito el 29 de junio del $2000 \mathrm{y}$ entró en vigencia el $1^{\circ}$ de agosto de ese mismo año.

La segunda etapa de la negociación se inició en abril de 2001, con la finalidad de firmar un Acuerdo definitivo para la conformación de una Zona de Libre Comercio entre ambos grupos. La importancia que los gobiernos de los países miembros de la Comunidad Andina y del Mercosur asignaron a la formación de una zona de libre comercio fue destacada en reiteradas oportunidades, al más alto nivel político, tanto presidencial como ministerial.

El 6 de diciembre de 2002, los países de la CAN y del Mercosur suscribieron, en Brasilia, un Acuerdo de Complementación Económica por medio del cual reiteraron su decisión de conformar un Área de Libre Comercio, "cuya negociación deberá estar concluida antes del 31 de diciembre de 2003" (CAN, 2009: 1). Los esfuerzos para profundizar los lazos económico-comerciales entre ambos bloques regionales entraban en la recta final.

Las bases para la integración efectiva de las economías venezolana y argentina se habían instalado exitosamente. Poco tiempo después, debido a la confluencia de una progresiva estabilización de la situación política y económica y al surgimiento de un contexto internacional favorable, la expansión de los vínculos materiales alcanzará niveles históricos.

\section{Segunda Sección}

\section{a. Cooperación política y profundización de las relaciones económicas}

De acuerdo a lo establecido en los apartados anteriores, a fines de la década del noventa, la dinámica económica de la relación bilateral exhibía un panorama poco alentador para los negocios entre argentinos y venezolanos. Del mismo modo, debido al estallido de un severo marco de inestabilidad política y económica en ambos países, los primeros años del siglo XXI tampoco parecían ofrecer signos favorables a la reversión de estas tendencias. ${ }^{10}$

El punto de inflexión de esta situación sobrevino en el transcurso de 2004, como resultado de la confluencia de dos factores de suma relevancia. Por un lado, el progresivo desarrollo de un marco internacional favorable a la región, en términos económicos. Por otro, la estabilización de los procesos políticos en ambas naciones y el surgimiento de intereses y objetivos de gobierno complementarios.

Respecto al primer punto, desde principios de 2003 la evolución de la economía internacional comenzó a experimentar cambios significativos que tuvieron un impacto decisivo para la recuperación del crecimiento de América Latina.

Durante los últimos años "el relanzamiento de la demanda internacional, motorizado en especial por la fuerte demanda china, contribuyó al crecimiento de la economía latinoamericana y a la mejora de los términos del intercambio" (Sevares, 2007: 11). Según la Conferencia de las Naciones Unidas sobre Comercio y Desarrollo (UNCTAD, 2006), los precios de los commodities aumentaron 44,8\% entre 2002 y 2005 en dólares corrientes, excluyendo el petróleo (que experimentó un incremento de un 114\%). Como se puede apreciar en el Gráfico $\mathrm{N}^{\circ} 3$, gracias 
a esta expansión de precios de los productos primarios, la región adquirió los ingresos necesarios que le permitieron solventar un notable aumento de sus flujos comerciales.

Gráfico 3. América Latina y el Caribe: tasas de crecimiento de las exportaciones e importaciones de bienes, $2001-2005$
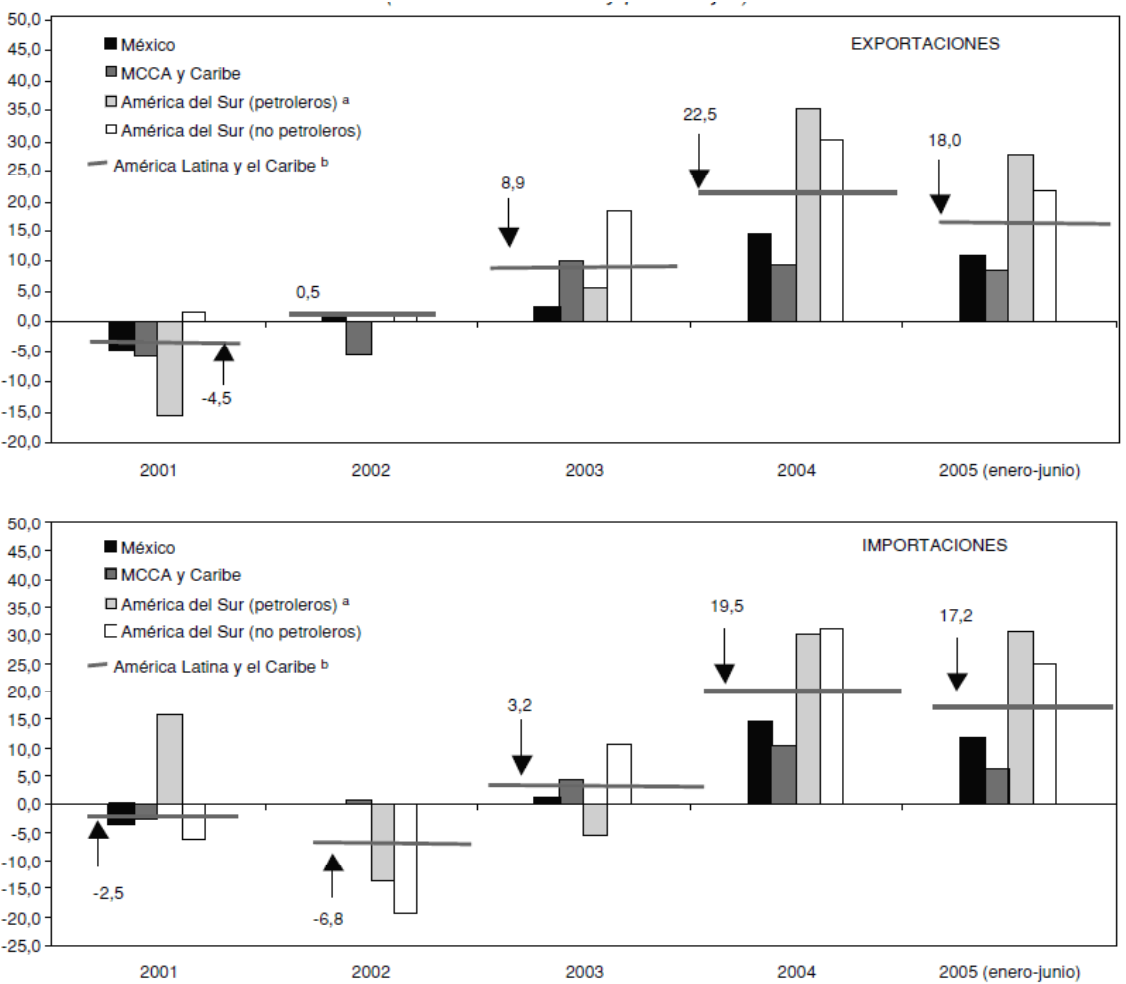

a. Los países petroleros de América del Sur son Colombia, Ecuador y República Bolivariana de Venezuela y los no petroleros son Argentina, Bolivia, Brasil, Chile, Paraguay, Perú y Uruguay.

b. Se agregan 37 países.

Fuente: CEPAL (2006)

Respecto al segundo factor, la asunción de Néstor Kirchner a mediados de 2003 en conjunto con la reafirmación del gobierno de Chávez, tras la victoria en el referéndum revocatorio de 2004, inauguró un nuevo marco de relaciones bilaterales caracterizado por el estrechamiento de la cooperación política ${ }^{11}$ y la intensificación de los vínculos económicos.

Ahora bien, detrás de esta nueva sintonía bilateral existieron una serie de circunstancias vinculadas a objetivos internos que tuvieron una influencia relevante. 
En primer lugar, del lado argentino, las modificaciones establecidas en el modelo de desarrollo implementado en este país permiten superar la situación de crisis pos 2001. En ese sentido las principales medidas implementadas por el gobierno de Néstor Kirchner incluyeron el sostenimiento de un tipo de cambio competitivo alrededor de los 3 pesos por dólar; el incremento constante del PBI industrial; los sectores líderes en la economía fueron la industria sustitutiva, la construcción, el agro y la producción petrolera reemplazando a las empresas privatizadas y las finanzas (Araya y Colombo, 2009).

Asimismo, la crisis energética empezaba a tener efectos negativos en diversas actividades productivas e incluso en las relaciones bilaterales con países vecinos, ante el incumplimiento de los compromisos en materia de exportación de gas. Por otra parte, debido a la incertidumbre que generaba una economía aún en bancarrota, existían fuertes restricciones para acceder al mercado financiero internacional. De este modo, la apertura de canales alternativos de financiación era un lujo que no se podía rechazar.

Del lado venezolano, debido al aumento fenomenal de los precios del crudo la disponibilidad de divisas se multiplicó exponencialmente. Esta verdadera bonanza petrolera favoreció la expansión del gasto público y posibilitó la puesta en marcha de programas de cooperación financiera con países de la región, como Argentina, que se vio beneficiada por compras millonarias de bonos del Estado. ${ }^{12}$ Por otra parte, las insuficiencias estructurales del sector agroalimentario nacional (Venezuela importa alrededor del $80 \%$ de sus alimentos), sumadas a las necesidades de infraestructura de la industria petrolera y a la puesta en marcha de ambiciosos proyectos de construcción (todos sectores donde nuestro país posee altos niveles de competitividad) hicieron posible una "simbiosis" bilateral sin precedentes.

La intensidad de estas fuerzas económicas puso rápidamente a tono las reglamentaciones y el marco legal necesarios para su mantenimiento y expansión. Durante el periodo de gobierno Kirchner-Chávez, gracias al desarrollo de un nuevo marco de cooperación política, se tendieron en pocos años las bases para la profundización de los vínculos económicos entre ambas naciones.

En este sentido, uno de los instrumentos internacionales que tuvo un impacto decisivo en las relaciones comerciales bilaterales comenzó a tomar forma en diciembre de 2003, durante la XXV Reunión del Consejo del Mercado Común en Montevideo. A partir de este encuentro, celebrado en el marco de los compromisos CAN-Mercosur, Argentina y Venezuela, junto con las economías andinas de Ecuador y Colombia, suscribieron un Tratado de Libre Comercio (TLC) que supuso un salto de gran relevancia en el proceso de integración económica regional. ${ }^{13}$

Dicho instrumento, protocolizado en ALADI en octubre de 2004 como Acuerdo de Complementación Económica $\mathrm{N}^{\circ} 59$ (ACE 59), entró en vigencia en enero de 2005 y estableció un cronograma de liberalización del comercio bilateral a 15 años que incluye la reducción de más de 1.200 partidas arancelarias que explican aproximadamente el $73 \%$ de las colocaciones argentinas en Venezuela.

Dentro de este marco, las exportaciones vinculadas a la producción de manufacturas de origen agropecuario (MOA) constituyen el rubro más beneficiado por 
los acuerdos, ya que, de acuerdo al análisis del CEI (Gaspar, 2006), las partidas incluidas dentro de la desgravación arancelaria explican casi la totalidad del valor de las exportaciones corrientes. Por su parte, aunque la baja de los aranceles a las manufacturas de origen industrial (MOI) incluye a una serie de partidas que explican el $35 \%$ de las ventas argentinas, la abierta preponderancia de este tipo de comercio da lugar a futuros acuerdos que derivarán en nuevas oportunidades para las manufacturas argentinas.

Paralelamente, en términos agregados, el proceso de desgravación comienza en 2005 con una reducción inicial del 33\% respecto al arancel promedio que grava el ingreso de los productos argentinos. Una vez implementada esta desgravación inicial, el proceso continúa con la puesta en marcha de una secuencia de desgravaciones escalonadas en el que los aranceles promedio disminuyen en alrededor de 7 puntos porcentuales por año hasta 2015, punto en que los aranceles habrán caído más del $95 \% .^{14}$

Un segundo instrumento bilateral que jugó un rol decisivo en el impulso de los vínculos económico-comerciales entre Argentina y Venezuela se originó en abril de 2004, a través de la conclusión del Convenio Integral de Cooperación y Anexos. De acuerdo con el CEI, la celebración de dicho tratado, al brindar facultades para monitorear y establecer nuevos vínculos comerciales y económicos en distintas áreas de interés común ${ }^{15}$, "incorporó las bases para mejorar el intercambio comercial entre ambas economías" (Pioli, 2006: 64).

Ahora bien, en términos generales, la puesta en marcha del convenio bilateral constituyó un esfuerzo conjunto para apuntalar deficiencias estructurales de ambas economías nacionales y apoyar los programas de desarrollo económico y social implementados por ambos gobiernos. ${ }^{16}$ De esta manera, entre las motivaciones generales para la construcción del acuerdo confluyeron, del lado argentino, la necesidad de obtener aprovisionamientos de hidrocarburos adicionales en aras de saltear los problemas inherentes a la crisis energética interna. Del lado venezolano, influyó la necesidad de asegurarse el acceso estable a una fuente importante de alimentos y tecnología agrícola capaz de complementar las deficiencias tradicionales del sector agroalimentario nacional y sostener el programa gubernamental de provisión de alimentos a precios subsidiados orientado a la satisfacción de las necesidades básicas de la población nacional de bajos recursos (MERCAL). ${ }^{17}$

El leitmotiv del convenio bilateral giraba entonces alrededor del intercambio de hidrocarburos venezolanos por bienes provenientes mayoritariamente del sector agroalimentario argentino. Con respecto a su funcionamiento y mecanismos concretos, es preciso destacar que los intercambios entre productos de ambas economías se canalizan, en líneas generales, de la siguiente manera. El Estado argentino, a través de la Compañía Administradora del Mercado Mayorista Eléctrico Sociedad Anónima (CAMMESA) compra gasoil y fuel-oil (producto que sustituye al gas como combustible para las centrales eléctricas), según lo requiera, a la estatal Petróleos de Venezuela Sociedad Anónima (PDVSA), que a partir de octubre de 2004 dispone de oficinas comerciales en Buenos Aires (Interven), con la finalidad de facilitar los vínculos comerciales. 
Los pagos que realiza CAMMESA por el combustible venezolano son depositados en un fondo de fideicomiso ${ }^{18}$ establecido especialmente en la cuenta del Banco Ubs Stamford de Nueva York y administrado por el banco estatal venezolano Banco de Desarrollo Social de Venezuela (BANDES), según instrucciones del Ministerio de Energía y Minas y PDVSA. Ahora bien, en el marco del convenio bilateral, la República Bolivariana se compromete a utilizar dichos fondos para la adquisición de productos provenientes de nuestro país a través de las necesidades de los distintos Ministerios o entes venezolanos inscriptos (la estatal Corporación de Abastecimiento y Servicios Agrícolas -CASA-, el Ministerio de Agricultura y Tierras, la Corporación Venezolana de la Guayana y la empresa PDVSA), de acuerdo a las previsiones de compras anuales que estos organismos establezcan y a la oferta exportable argentina, realizándose las compras bajo el criterio de reciprocidad y equilibrio del intercambio comercial. ${ }^{19}$

Dentro del abanico de oportunidades de intercambio que ofrecen ambas economías, el convenio especifica, a través de sus anexos y addendums posteriores (trece hasta enero de 2009), un listado de bienes y servicios particulares que entran bajo su mandato. En términos generales, las áreas de interés incluidas en el marco del acuerdo se vinculan con productos agroalimentarios, equipos e insumos para la industria petrolera, equipamiento médico y productos farmacéuticos, aeronáutica, construcción e infraestructura, energía, deportes y salud. Gracias a este marco, un número cada vez mayor de productos exportables argentinos reciben un trato preferencial en el acceso al mercado venezolano.

Por otra parte, además de objetivos comerciales inmediatos, el Convenio Integral argentino-venezolano prevé entendimientos en materia de cooperación científico-tecnológica. En este sentido, establece vinculaciones de organismos de investigación o desarrollo tecnológico de ambos países (el Instituto de Investigación Aplicadas -INVAP- y el Instituto Nacional de Tecnología Agropecuaria -INTA- por la Argentina; y el Instituto de Tecnología Venezolana para el Petróleo -INTEVEP- y el Instituto Venezolano de Investigaciones Científicas -IVIC- por Venezuela) para promover el intercambio de profesionales, técnicos y productores para compartir experiencias y fomentar la cooperación y el desarrollo. De esta manera, la puesta en marcha de este acuerdo bilateral supone una respuesta coordinada en busca de una mayor integración económica, cuyos pilares se encuentran no sólo en la intensificación de los intercambios comerciales sino que se pone el acento también en la generación de conocimiento y el desarrollo técnico orientado a la producción.

La primera oportunidad para someter a prueba el convenio se dio tres meses después de la conclusión del acuerdo, a través de la organización de la Macrorueda de negocios entre Argentina y Venezuela, llevada a cabo en la Isla Margarita en julio de 2004. De acuerdo con Luis Bilbao, "el encuentro inter-empresario fue exitoso más allá de lo esperado"20 (Bilbao, 2004: 8).

El ministro de Producción y Comercio de Venezuela, Willmar Castro Soteldo, informó que participaron 145 empresas argentinas y 355 venezolanas y se concretaron 157 negocios por un monto de 80,4 millones de dólares. Por su parte, 
el presidente del Bancoex de Venezuela, Víctor Álvarez, anunció la firma de una línea de crédito entre la entidad que dirige y el Banco de Integración y Comercio Exterior (BICE) y el Credicoop de Argentina, dirigida fundamentalmente a las microempresas, pequeñas empresas y cooperativas, e informó acerca de un memorando de entendimiento entre PDV Marina Venezuela y la Unión Transitoria de Empresas (UTE); otro entre la Compañía Diques y Astilleros Nacionales (Dianca) y los Astilleros Río Santiago de Argentina, además de una carta de intención entre los gobiernos del estado Nueva Esparta y los astilleros de Río Santiago, con el objetivo de construir un ferry para Isla Margarita. Álvarez anunció asimismo la creación del Fondo Latinoamericano de Garantías Recíprocas para avalar a pymes cuando soliciten créditos y la introducción en Venezuela de tarjetas de crédito y débito especialmente diseñadas para las cooperativas (Bilbao, 2004: 8).

Los resultados materiales de esta intensificación de los lazos bilaterales no se hicieron esperar. Como puede apreciarse en el Gráfico $\mathrm{N}^{\circ} 4$, durante el primer año de implementación del Convenio, el valor de las exportaciones argentinas verificó, por mucho, el punto más alto de la serie histórica, creciendo en un $300 \%$ respecto al 2002, y manteniendo un ritmo sostenido de incremento exponencial (Gaspar, 2005: 10).

Gráfico 4. Intercambio comercial de Argentina con Venezuela, 20002008

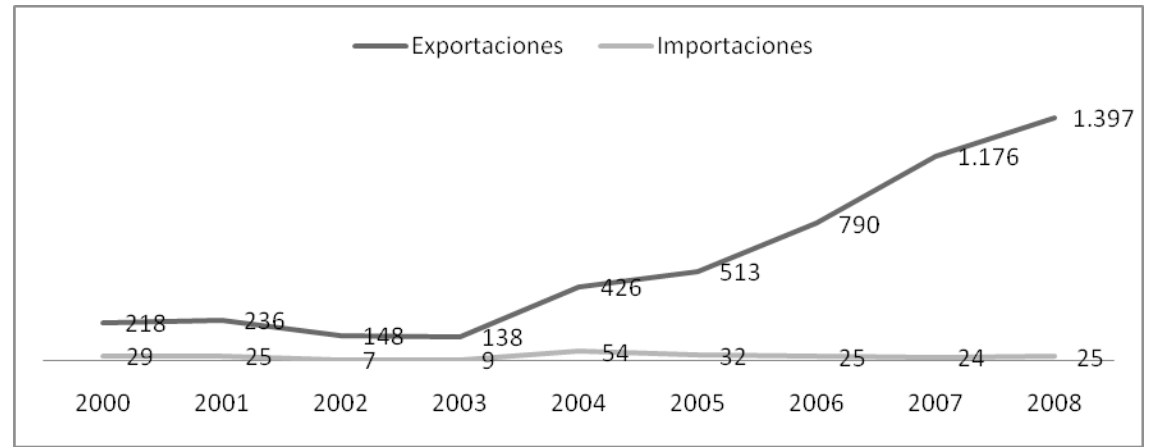

Fuente: Elaboración propia en base a datos de CEI (2009)

En este sentido, el peso de los acuerdos económicos alcanzados por ambas administraciones fue determinante. Así lo remarcaba el CEI en un estudio del panorama comercial bilateral de 2005: "A propósito de estos acuerdos se identifican varios productos donde nuestro país incrementó fuertemente sus exportaciones a Venezuela, por ejemplo, el caso de la leche. Asimismo, hubo otros donde la participación argentina en las importaciones venezolanas era nula en 2003 y experimentaron un gran salto hacia 2005. En muchos casos, estos productos no muestran complementariedad comercial entre la Argentina y Venezuela y el Convenio, conjuntamente con el estrechamiento del vínculo bilateral, ha jugado un papel fundamental en el incremento de las exportaciones" (Pioli, 2006: 65). 
De este modo, durante los últimos ocho años el volumen de comercio bilateral se ha incrementado exponencialmente en relación con los primeros años del nuevo milenio. Ahora bien, el dato que llama la atención es la reducida participación de las importaciones venezolanas en el comercio total (menos del $2 \%$ de los flujos bilaterales). Si bien la causa de este fenómeno no resulta del todo clara ${ }^{21}$, la razón más convincente se desprende de dos elementos que pueden prestarse a confusión.

En primer lugar, de acuerdo al testimonio de la Gerencia General de Divulgación Estadística de Venezuela, las fuentes primarias encargadas de elaborar las estadísticas comerciales de dicho país -el Instituto Nacional de Estadística (INE) y el Banco de Exportaciones de Venezuela (BANCOEX) ${ }^{22}$, en el cálculo global de los intercambios de Venezuela no tienen en cuenta las exportaciones de petróleo del sector público (es decir las de PDVSA), sino que contabilizan únicamente aquellas vinculadas a los sectores no tradicionales (todos los productos que difieren del hierro y el petróleo). La contabilización de la comercialización externa del crudo y sus derivados queda en manos de la propia PDVSA y del Ministerio para la Energía y el Petróleo, cuyos datos no se encuentran disponibles para consulta pública.

Los principales productos de exportación de Venezuela, tanto para la Argentina como para el resto del mundo, tienen que ver precisamente con el rubro energético, que, como subrayáramos en el primer apartado, se encuentra casi totalmente bajo propiedad del Estado. De esta forma, a raíz de estas excepciones fundamentales se genera una falta de información sobre un conjunto de bienes clave para la vinculación económica bilateral ${ }^{23}$ que plantea ciertas dudas respecto a los flujos comerciales reales entre Argentina y Venezuela. ${ }^{24}$

Un segundo elemento de controversia tiene que ver con los mecanismos financieros establecidos bajo el amparo del Convenio Integral. Debido a que el sistema de pagos de las transacciones generadas en el marco del Convenio se hace efectivo a través de un fondo fiduciario y no a través de los canales estándares, es posible que escapen a los procesos de regulación y contabilización tradicionales. Si tenemos en cuenta estas dos aclaraciones es dable entender porqué Venezuela en 2007, siendo ya miembro de una alianza estratégica con Argentina ${ }^{25}$, posee menos relevancia que la pequeña Isla de Bahamas como proveedor de importaciones al mercado nacional. ${ }^{26}$

Más allá de estas controversias, lo cierto es que el volumen de los intercambios se incrementó en forma significativa, y dentro de esta dinámica las exportaciones argentinas tuvieron una altísima performance. De acuerdo con datos de ALADI, volcadas en el Cuadro $\mathrm{N}^{\circ} 2$, entre 2003 y 2008 Argentina multiplicó por 10 el volumen total de las ventas colocadas en el mercado venezolano, pasando de 138 millones de dólares en 2003 a 1.422 millones en 2008, lo que le permitió ubicarse entre los principales países de destino de las ventas nacionales. 
Cuadro 2. Exportaciones argentinas a Venezuela y al mundo (en millones de US\$)

\begin{tabular}{lrrrrrrr}
\hline $\begin{array}{l}\text { Exportaciones de } \\
\text { Argentina }\end{array}$ & $\mathbf{2 0 0 2}$ & $\mathbf{2 0 0 3}$ & $\mathbf{2 0 0 4}$ & $\mathbf{2 0 0 5}$ & $\mathbf{2 0 0 6}$ & $\mathbf{2 0 0 7}$ & $\mathbf{2 0 0 8}$ \\
\hline A Venezuela & 148 & 138 & 426 & 513 & 790 & 1.176 & 1.397 \\
\hline Al mundo & 25.709 & 29.566 & 34.550 & 40.387 & 46.456 & 55.779 & 70.043 \\
\hline Participación (\%) & 0,58 & 0,47 & 1,23 & 1,27 & 1,70 & 2,11 & 1,99 \\
\hline
\end{tabular}

Fuente: Elaboración propia en base a datos de CEI (2009)

De esta manera, la República Bolivariana se convirtió en el cuarto mercado más importante de las exportaciones argentinas hacia destinos latinoamericanos, después de Brasil ${ }^{27}$, Chile y Uruguay. En contraste, y teniendo en cuenta las salvedades anteriormente comentadas, el país caribeño es origen de sólo el $0,1 \%$ de las compras argentinas del 2008, ubicándose entre los últimos puestos (Ver Cuadro $\mathrm{N}^{\mathrm{o}} 3$ ).

Cuadro 3. Argentina: exportaciones e importaciones según destinos (2008)

\section{Exportaciones}

\begin{tabular}{rlrr}
\hline & \multicolumn{1}{c}{ País } & \multicolumn{1}{c}{ Valor } & \% Total \\
\hline $\mathbf{1}$ & Brasil & 13.243 & 18,9 \\
$\mathbf{2}$ & China & 6.394 & 9,1 \\
$\mathbf{3}$ & Estados & 5.188 & 7,4 \\
& Unidos & & \\
$\mathbf{4}$ & Chile & 4.672 & 6,7 \\
$\mathbf{5}$ & Países Bajos & 2.954 & 4,2 \\
$\mathbf{6}$ & España & 2.798 & 4,0 \\
$\mathbf{7}$ & Uruguay & 1.764 & 2,5 \\
$\mathbf{8}$ & Italia & 1.674 & 2,4 \\
$\mathbf{9}$ & Alemania & 1.514 & 2,2 \\
$\mathbf{1 0}$ & Venezuela & $\mathbf{1 . 3 9 8}$ & $\mathbf{2 , 0}$ \\
& Total & 70.044 & 100 \\
\hline
\end{tabular}

Importaciones

\begin{tabular}{llrr}
\hline & \multicolumn{1}{c}{ País } & \multicolumn{1}{c}{ Valor } & \multicolumn{1}{c}{ \%Total } \\
\hline $\mathbf{1}$ & Brasil & 17.689 & 30,8 \\
$\mathbf{2}$ & China & 7.104 & 12,4 \\
$\mathbf{3}$ & Estados & 6.895 & 12,0 \\
& Unidos & & \\
$\mathbf{4}$ & Alemania & 2.534 & 4,4 \\
$\mathbf{5}$ & Paraguay & 1.770 & 3,1 \\
$\mathbf{6}$ & México & 1.595 & 2,8 \\
$\mathbf{7}$ & Francia & 1.449 & 2,5 \\
$\mathbf{8}$ & Japón & 1.378 & 2,4 \\
$\mathbf{9}$ & Italia & 1.205 & 2,1 \\
$\mathbf{6 5}$ & Venezuela & $\mathbf{3 5}$ & $\mathbf{0 , 1}$ \\
& Total & 57.413 & 100 \\
\hline
\end{tabular}

Fuente: Elaboración propia en base a datos de CEI (2009)

Adicionalmente, de acuerdo con INTAL una manera de apreciar la importancia relativa de un socio comercial consiste en comparar la participación que tiene para un país con la que tiene en el comercio mundial. De esta manera, las frases "compra mucho" o "compra poco" se colocan en contexto (Girado et al., 2006: 96).

Un indicador que permite medir esta interrelación relativa es el Índice de Intensidad del Comercio (IIC) utilizado por Anderson y Norheim (1994). Dicho indicador, según el CEI, se define como la proporción del comercio de un país con un socio en relación a la proporción que representa el país socio en el comercio mundial (CEI, 2007). En consecuencia el IIC permite distinguir la parte del co- 
mercio explicada por el patrón de especialización de las economías, por un lado, y aquella originada en un "sesgo geográfico" residual, por el otro. De esta manera, ofrece una visión alternativa sobre la naturaleza e importancia de los cambios en los flujos bilaterales de comercio. El análisis de los cambios en el índice puede mostrar si con el tiempo dos países están experimentando una tendencia creciente o decreciente a comerciar entre sí.

En el Gráfico $\mathrm{N}^{\mathrm{o}} 5$ se proyectan los resultados del IIC para el comercio entre Argentina y Venezuela durante el periodo 2000-2008. Dentro de las posibilidades que ofrece el cálculo, un índice mayor a 1 significa que los países bajo análisis tienen un comercio bilateral mayor al que se esperaría en función de la participación del socio comercial en el comercio mundial (existencia de sesgo geográfico positivo). A la luz de los valores obtenidos, éste parece ser el caso para los intercambios bilaterales argentino-venezolanos. En consecuencia, es posible afirmar que ambas economías están experimentando una tendencia creciente a comerciar entre sí.

Gráfico 5. Índice de Intensidad del Comercio (IIC), Argentina Venezuela

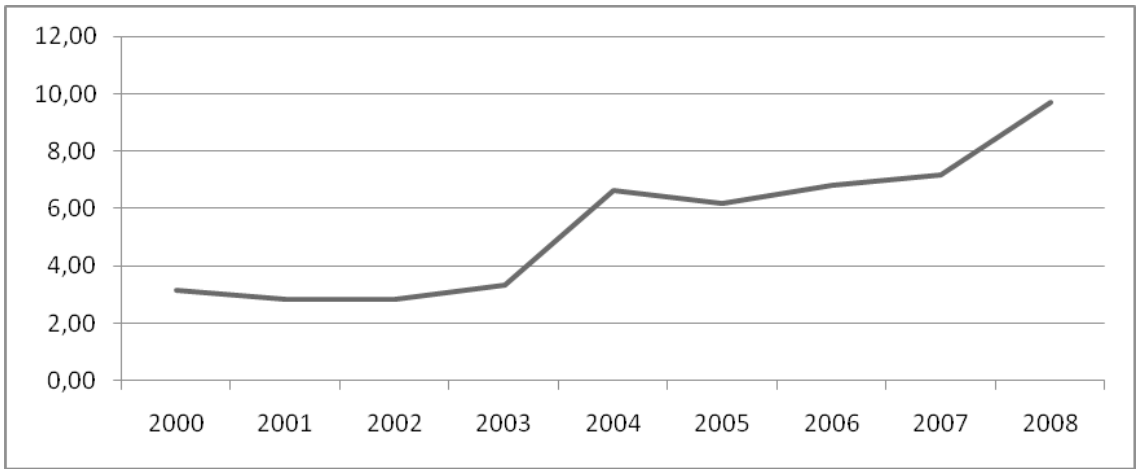

Fuente: Elaboración propia en base a datos de CEI (2008, 2009); ALADI (2009) y OMC $(2004,2005,2006,2007,2008)$

Por último, otro rasgo sobresaliente en la estructura de los intercambios bilaterales tiene que ver con el desarrollo de un marcado desequilibrio comercial entre ambas naciones, con resultados favorables a nuestro país. Como se desprende del análisis del Gráfico $\mathrm{N}^{\mathrm{o}} 6$, durante los últimos nueve años Argentina ha experimentado un progresivo crecimiento de su saldo comercial con Venezuela, alcanzando un pico de 1.372 millones de dólares en 2008. De esta manera, a pesar de que las cifras referidas a las importaciones de origen venezolanas (que podrían tener un impacto en la balanza comercial bilateral) se encuentran sujetas a revisión, el crecimiento exponencial de las exportaciones argentinas con destino a Venezuela, gracias a las desgravaciones arancelarias sobre productos en las cuales nuestro país tiene una tradicional competitividad internacional, constituye un factor relevante para el análisis del superávit comercial nacional con la República Bolivariana. 
Gráfico 6. Balanza comercial de Argentina con Venezuela, 1999-2008 (en millones de US\$)

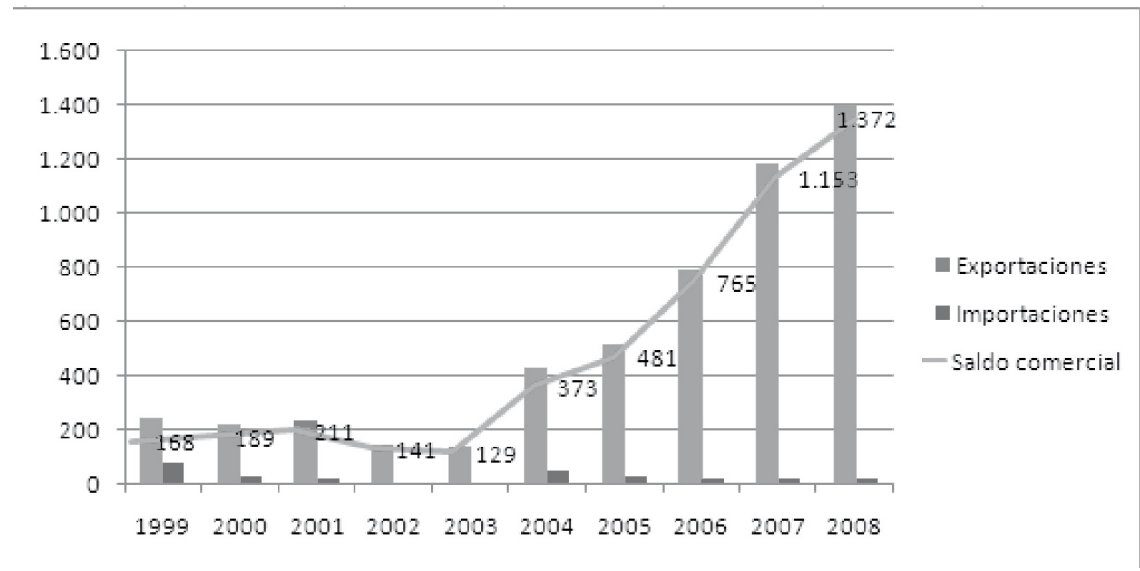

Fuente: Elaboración propia en base a datos de CEI y CCAV (Cámara de Comercio Argentino-Venezolana)

\section{b. Composición del comercio Argentina - Venezuela}

\section{b.1 Exportaciones}

De acuerdo con datos elaborados por el INDEC, durante el año 2007 las exportaciones argentinas a Venezuela alcanzaron los 1.176 millones de dólares. De esa suma, las manufacturas de origen industrial (MOI) se erigieron como el rubro más dinámico de la relación bilateral, obteniendo un crecimiento del $763 \%$ entre 20032006 (CEP, 2007b: 70) y una participación dominante del 71\% del total de las colocaciones argentinas. En segundo lugar de importancia se ubicaron las manufacturas de origen agropecuario (MOA), con el 24,5\%; seguidas por los productos primarios $(3,9 \%)$; y los bienes pertenecientes al rubro de combustibles y energía $(0,06 \%)$ (Ver Gráfico No 7$)$.

Dentro de las MOI, las industrias básicas de hierro y acero, el sector automotriz y la industria química, tuvieron una participación destacada. Las ventas de automóviles, durante el 2007, lograron colocarse al tope de la lista de los principales productos de exportación, concentrando el $11 \%$ del total. Los tractores, camiones y demás vehículos de transporte de mercancías también exhibieron números relevantes, logrando posicionarse en el tercer y quinto lugar, respectivamente, dentro de los productos exportados de mayor participación.

Respecto a las industrias básicas, los principales rubros de venta se vinculan con las necesidades venezolanas de infraestructura para la industria de hidrocarburos y la siderurgia. Es así que, dentro de los principales productos de exportación de este sector, la provisión de tubos de acero para la construcción de oleoductos y gasoductos y los recipientes para gas comprimido o fundición, tuvieron un papel preponderante. 
Gráfico 7. Exportaciones argentinas a Venezuela por grandes rubros

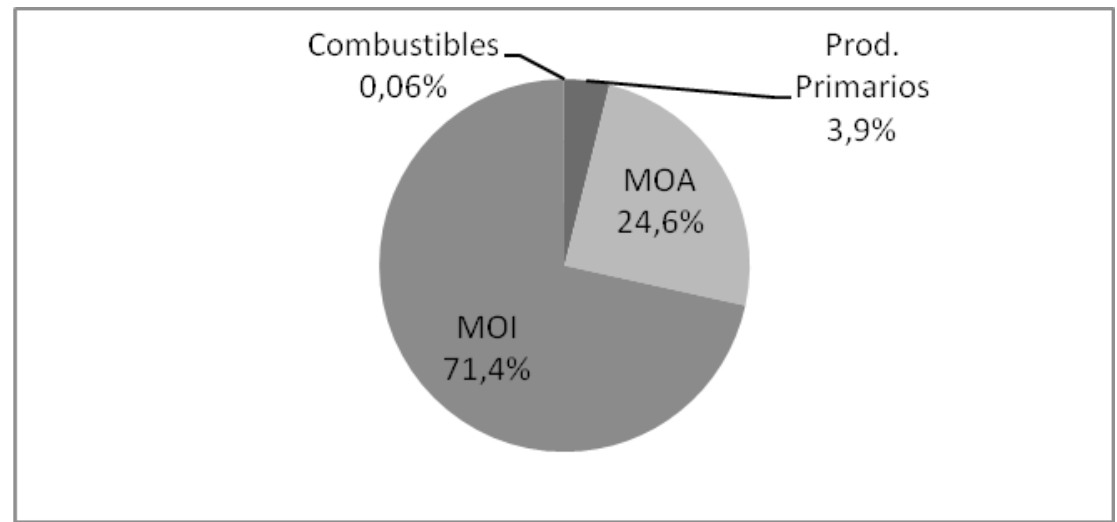

Fuente: Elaboración propia en base a datos del INDEC

En lo referido a las industrias químicas, dentro del sector orgánico se destacaron las ventas de Etileno (0,3\% de las exportaciones totales), mientras que en el rubro inorgánico, el monóxido de plomo obtuvo una participación de alrededor del $0,4 \%$, igualando las ventas totales de productos tradicionales como el trigo.

Cuadro 4. Argentina: principales productos de exportación a Venezuela (2007)

\begin{tabular}{rlcc}
\hline & Descripción & \%Total & \%Acum. \\
\hline $\mathbf{1}$ & Automóviles & 11.10 & 11.10 \\
$\mathbf{2}$ & Aceite de soja & 5.94 & 17.03 \\
$\mathbf{3}$ & Tractores & 5.91 & 22.94 \\
$\mathbf{4}$ & Leche entera & 4.57 & 27.52 \\
$\mathbf{5}$ & Vehículos de transporte & 4.25 & 31.77 \\
$\mathbf{6}$ & Carne bovina & 4.25 & 36.02 \\
$\mathbf{7}$ & Tubos de acero sin revestir & 3.91 & 39.93 \\
$\mathbf{8}$ & Autopartes & 3.45 & 43.38 \\
$\mathbf{9}$ & Leche modificada & 2.41 & 45.79 \\
$\mathbf{1 0}$ & Tubos de acero aleados & 2.27 & 48.06 \\
\hline
\end{tabular}

Fuente: Elaboración propia en base a datos de ALADI

Otro rubro que ha experimentado un progresivo crecimiento en las exportaciones argentinas hacia el mercado venezolano se vincula con la industria farmacéutica. De acuerdo con datos de ALADI, entre 1999 y 2007, dicho sector ha multiplicado por tres su participación en las exportaciones totales de Argentina 
hacia Venezuela, posicionando varios ítems dentro de los 30 principales productos de intercambio comercial.

En el caso de las MOA, los bienes de mayor participación se refieren sobre todo a los rubros vinculados a la industria agroalimentaria. La producción venezolana de este tipo de productos presenta una serie de deficiencias estructurales que lo han llevado a convertirse en un importador neto de alimentos. De esta manera, como puede apreciarse en el Cuadro $\mathrm{N}^{\circ} 4$, el aceite de soja junto con la carne bovina congelada y los productos lácteos ocupan un lugar relevante entre los diez primeros productos de exportación. A ellos se suman, aunque más rezagados, productos como la harina de malta, vino de uvas, residuos de la extracción de aceite de soja, etc.

Por último, en relación a las exportaciones de productos primarios, los productos de mayor importancia corresponden a las ventas de hortalizas (ocupando el lugar décimo tercero entre los principales productos de exportación), y cereales como el trigo y el maíz. Respecto a los bienes pertenecientes a la categoría "combustibles y energía", dos productos concentran alrededor del $80 \%$ del total del rubro: parafina y desechos de aceite.

\section{b.2 Cambios en la composición de la estructura comercial bilateral}

Un elemento de especial relevancia en la relación económica entre ambos países lo constituye la progresiva evolución de las exportaciones argentinas desde un perfil esencialmente primario-exportador hacia otro compuesto mayoritariamente por productos elaborados de origen industrial.

Gráfico 8. Composición de las exportaciones de Argentina a Venezuela (1999)

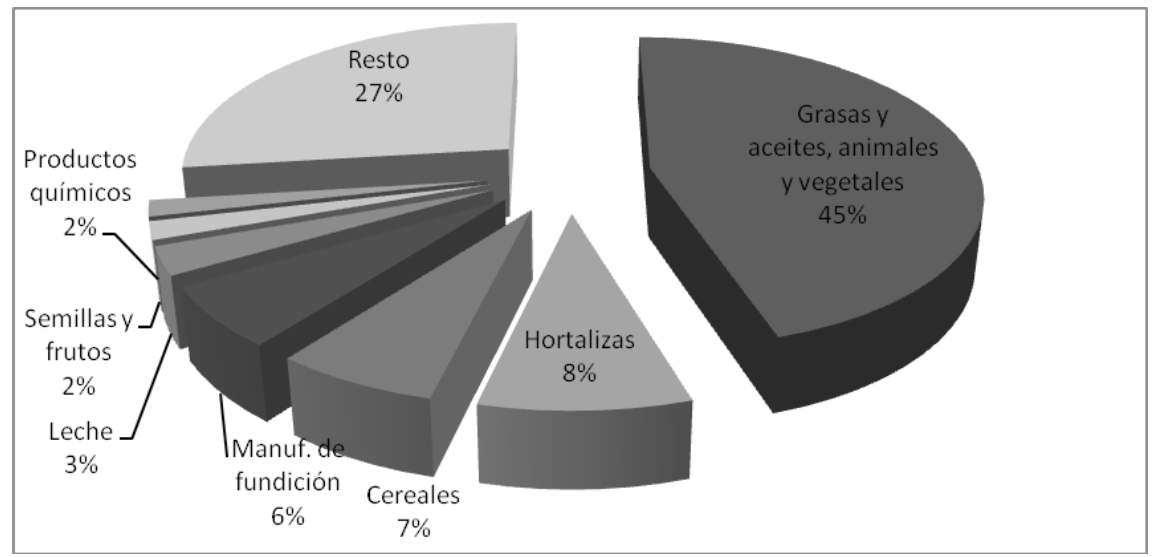

Fuente: Elaboración propia en base a datos de ALADI

Como puede apreciarse en el Gráfico $\mathrm{N}^{\circ} 8$, en 1999 el rubro de mayor participación en las exportaciones argentinas hacia Venezuela fue Grasas y aceites (45\%), seguido por Hortalizas y legumbres sin elaborar (8\%); Cereales (7\%); Metales 
comunes y sus manufacturas (6\%); Leche y productos lácteos (3\%); Productos químicos $(2 \%)$ y Semillas y frutos $(2 \%)$. Esto significa que, con excepción de los Productos químicos y las Manufacturas de fundición, todos los productos de mayor participación en las ventas son de un nivel de valor agregado relativamente bajo.

En el Gráfico $\mathrm{N}^{\circ} 9$, correspondiente a las ventas argentinas a Venezuela durante el año 2007, la composición de las exportaciones sufre importantes transformaciones en su estructura. De acuerdo con datos de ALADI, la mayor participación en los envíos al mercado bolivariano corresponde, en este caso, a los rubros de Automóviles y material de transporte (31\%), seguidos por Manufacturas de fundición de hierro o acero (8\%), Carnes y despojos (7\%), Grasas y aceites (6\%), Leche y productos lácteos $(5 \%)$, Maquinas y material eléctrico (5\%) y Productos farmacéuticos (3\%). Vale decir que, salvo Carnes, Productos lácteos y Grasas y aceites, el resto de los rubros con mayor participación en las exportaciones a Venezuela se caracterizan por ser de mediano o alto valor agregado (sumando en conjunto alrededor del $50 \%$ del total).

Gráfico 9. Composición de las exportaciones de Argentina a Venezuela (2007)

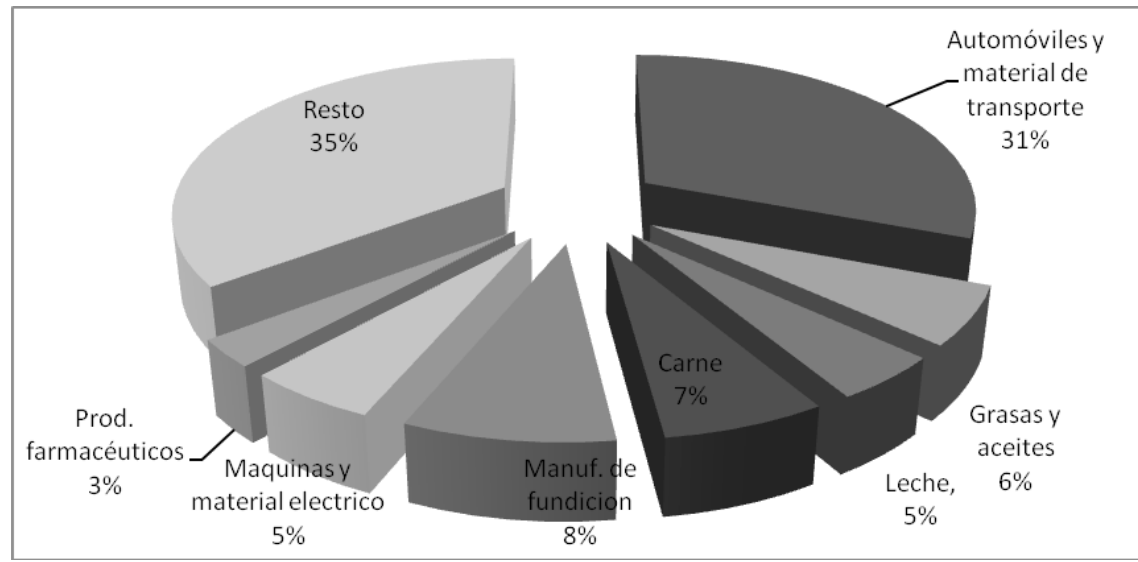

Fuente: Elaboración propia en base a datos de ALADI

\section{b.3 Importaciones}

Como se adelantó previamente, de acuerdo al análisis de los datos oficiales las compras argentinas de origen venezolano tienen una escasa relevancia en la cuenta global de nuestro país, ubicándose en el lugar 65 entre los principales proveedores de la economía nacional.

No obstante, de acuerdo con datos de ALADI, durante el año 2007 el valor de las importaciones provenientes de Venezuela alcanzó un total de 25 millones de dólares. Si ordenamos este valor global en categorías conforme a los usos econó- 
micos de las mercancías importadas, se obtiene el panorama de los intercambios bilaterales que a continuación se detalla.

Del análisis del Gráfico $\mathrm{N}^{\circ} 10$, es posible concluir que, en lo referente a las compras argentinas provenientes de Venezuela, los bienes intermedios concentran más de la mitad de lo importado y, en conjunción con las piezas y accesorios para bienes de capital, suman alrededor del $90 \%$ del total de las mercancías adquiridas por nuestro país. De esta forma, la participación de productos elaborados vuelve a ser protagonista en los intercambios bilaterales, esta vez bajo la forma de importaciones de origen venezolano.

Gráfico 10. Importaciones de origen venezolano, por uso económico (2007)

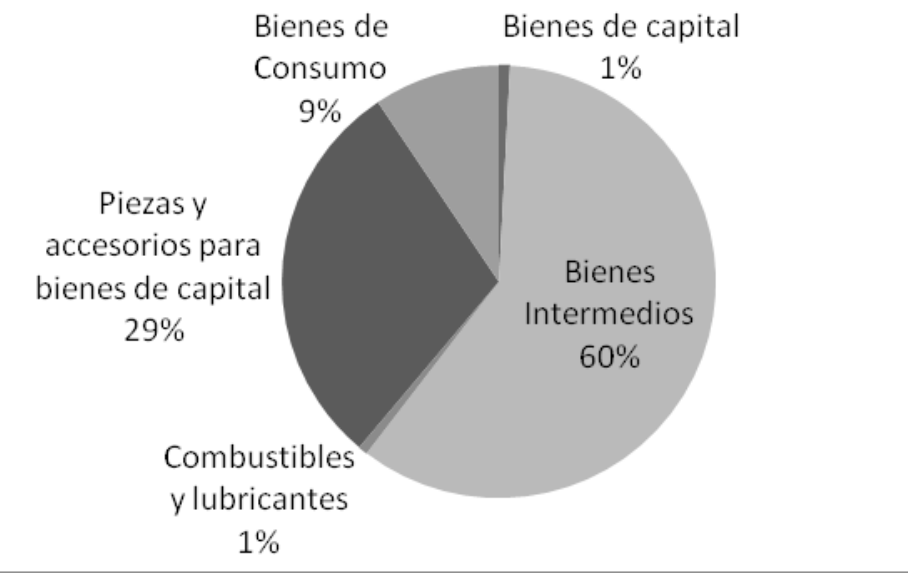

Fuente: Elaboración propia en base a datos del INDEC

Asimismo, en términos desagregados, diez productos provenientes de la República Bolivariana concentran alrededor del $70 \%$ del total de las compras efectuadas por Argentina. Dentro de esa suma, como puede apreciarse en el Cuadro $\mathrm{N}^{\mathrm{o}} 5$, se destacan las manufacturas de aluminio $(14,7 \%)$, los instrumentos de perforación o sondeo $(11,7 \%)$ y el coque de petróleo $(11,2 \%)$, producto que se utiliza como combustible en la industria cementera y en cerámica, así como en algunas compañías eléctricas. 
Cuadro 5. Argentina: principales productos de importación desde Venezuela

\begin{tabular}{llcc}
\hline \multicolumn{1}{c}{ Producto } & \%Total & \%Acum \\
\hline $\mathbf{1}$ & Manufacturas de aluminio & $14.71 \%$ & $14.71 \%$ \\
$\mathbf{2}$ & Instrumentos de perforación o sondeo & $11.76 \%$ & $26.47 \%$ \\
$\mathbf{3}$ & Coque de petróleo & $11.29 \%$ & $37.77 \%$ \\
$\mathbf{4}$ & Navajas y máquinas de afeitar & $7.94 \%$ & $45.71 \%$ \\
$\mathbf{5}$ & Etilenglicol (etanodiol) & $7.76 \%$ & $53.48 \%$ \\
$\mathbf{6}$ & Dióxido de silicio & $6.99 \%$ & $60.46 \%$ \\
$\mathbf{7}$ & Carburos de silicio & $3.64 \%$ & $64.10 \%$ \\
\hline $\mathbf{8}$ & Colorantes & $2.56 \%$ & $66.67 \%$ \\
$\mathbf{9}$ & Vidrio & $1.27 \%$ & $67.94 \%$ \\
$\mathbf{1 0}$ & Partes de máquinas de perforación o sondeo & $1.18 \%$ & $69.11 \%$ \\
\hline
\end{tabular}

Fuente: Elaboración propia en base a datos de TRADEMAP

\section{Consideraciones finales}

El análisis de la historia reciente de los vínculos económicos bilaterales entre Argentina y Venezuela permite identificar dos etapas claramente diferenciadas. La primera se inició en 1990, en el marco del auge del libre mercado y el regionalismo abierto, y experimentó un declive abrupto a principios del nuevo milenio. La segunda tuvo lugar entre 2003 y 2008, como consecuencia de la estabilización de las crisis internas, el surgimiento de un entorno regional favorable y el establecimiento de un nuevo marco de cooperación bilateral. Durante este periodo, las relaciones económicas argentino-venezolanas experimentaron un salto cualitativo y cuantitativo.

En primer lugar, los vínculos financieros entre ambas naciones aumentaron exponencialmente y continuaron ocupando un lugar destacado, al representar valores totales superiores a los intercambios bilaterales de bienes. Sin embargo, a diferencia de la dinámica observada durante la década del noventa, a partir de 2003, los flujos de capitales sufrieron transformaciones relevantes respecto a los actores, destinos y modalidades. Por un lado, el sector privado argentino y las IED disminuyeron notablemente su protagonismo cediendo su lugar casi completamente a las negociaciones entre Estados a través de la compra-venta de bonos y títulos de deuda. Por otro, como consecuencia de la reducción de las colocaciones nacionales y del surgimiento de Venezuela como uno de los principales proveedores de capitales, (gracias a la compra masiva de bonos del Estado argentino), la dirección de los flujos de capitales se revirtió en favor de nuestro país.

En segundo lugar, respecto a las relaciones comerciales bilaterales, las tendencias que se abren a principios del nuevo milenio indican el inicio de una nueva etapa histórica, caracterizada de un lado, por la intensificación de los intercambios entre ambas economías y del otro, por el desarrollo progresivo de un patrón de 
relacionamiento distinto al imperante durante los años noventa, orientado a una mayor participación de bienes elaborados en la composición de los intercambios bilaterales.

En relación con el primer punto, gracias al impulso brindado por el Convenio Integral y el ACE 59, durante el periodo 2003-2008, el valor total de los intercambios entre ambas naciones experimentó un incremento record de alrededor del $970 \%$. Dentro de esta notable expansión de los vínculos comerciales, el crecimiento de las exportaciones argentinas hacia el mercado venezolano ha tenido una importancia determinante. En este sentido, si bien el volumen total de los intercambios bilaterales pasó de 146 millones de dólares en 2003 a 1.422 millones en 2008 , durante el mismo periodo las colocaciones argentinas en la cuenta comercial global tuvieron una participación promedio del $95 \%$.

Ahora bien, a pesar de que estas cifras indican la existencia de un importante desequilibrio en las relaciones comerciales bilaterales, es posible que las importaciones argentinas de combustibles venezolanos en el marco del Convenio Integral no estén debidamente registradas debido a los mecanismos financieros especiales que prevé la puesta en marcha de dicho instrumento.

En cuanto a la evolución del patrón de relación comercial es preciso destacar que durante los últimos años se ha iniciado una tendencia a incrementar el valor agregado de las exportaciones argentinas hacia el mercado venezolano. El análisis comparado de la composición de las relaciones comerciales bilaterales entre los años 1999 y 2007, ha dado como resultado que los productos de origen primario y sus manufacturas han bajado su participación, para dar lugar a un mayor volumen de intercambio de productos de origen industrial.

Por tanto, gracias a la profundización de los vínculos económico-comerciales $\mathrm{y}$ al establecimiento de un marco de regulación normativo capaz de sostener y ampliar los límites de dicha expansión, Venezuela presenta grandes oportunidades para las ventas de productos argentinos, tanto de carácter tradicional como no convencional. $\left.\int^{m}\right\}_{0,0}^{m}$

\section{Referencias}

1. Comunidad Andina de Naciones.

2. Mercado Común del Sur.

3. Para más información ver sitio web de OPEP: http://www.opec.org/home/basket.aspx.

4. "Las inversiones argentinas en Venezuela registraron ese año un salto histórico espectacular de 1.070 millones de dólares, con un aumento del $400 \%$ respecto de períodos anteriores" (Vinogradoff, 1997: 16).

5. El Plan de Convertibilidad, elaborado por el Ministerio de Economía a cargo de Domingo Cavallo, tuvo como objetivo establecer una moneda estable y lograr "una rápida desinflación" (Fanelli, 1999: 89), que permitió alcanzar cierta estabilidad. Comenzó a aplicarse en marzo de 1991, y significó el establecimiento de la paridad uno a uno del peso con el dólar de los Estados Unidos y la eliminación del financiamiento del déficit a través de la emisión de dinero.

6. La crisis de México (1994-1995), luego la de Asia (1997-1998) y finalmente la de Brasil (1999).

7. Ver sitio web de la OPEP: http://www.opec.org/home/basket.aspx.

8. En 1994, 1996 y 1998 el crecimiento del PBI venezolano dio cifras negativas: -2,8, -0,2 y -0,7 
respectivamente. La balanza de pagos también tuvo un signo deficitario: en 1994 fue de 303 millones de dólares, en 1995 de 1.120 y en 1998 de 3.418. Las reservas internacionales del Banco Central disminuyeron en un $40 \%$, la tasa de cambio de la moneda nacional sufrió una drástica devaluación pasando de 149 (Bs./US\$) en 1994 a 542,20 (Bs./US\$) en 1998. El déficit en las finanzas públicas fue en aumento durante esos años, acumulando 1.575 millones de dólares en 1998. Esta situación tuvo un fuerte impacto en la calidad de vida de la población disparando los niveles de desempleo y pobreza de los venezolanos. (Maza Zavala, 2007: 139).

9. En esta instancia es preciso recordar que Venezuela venía de sufrir una enorme revuelta popular en 1989 (el "caracazo"), dos intentos de golpes de Estado en 1992, y la destitución del presidente Carlos Andrés Pérez por corrupción y malversación de fondos en 1993.

10. Cabe recordar la crisis política venezolana de abril de 2002, que incluyó un intento de golpe de Estado y el posterior establecimiento de un "lockout" petrolero con severos efectos sobre la economía nacional. Por otro lado, Argentina se encontraba inmersa en un periodo de transición política y recuperación económica tras el estallido de la crisis de 2001.

11. Según revela el Centro de Estudios Unión para una Nueva Mayoría (CEUNM), en los últimos cuatro años Argentina no sólo ha suscrito con Venezuela más tratados que con el resto de los países de la región, sino que del total de los acuerdos alcanzados desde principios del siglo XX hasta el presente, casi el $40 \%$ corresponden al periodo de gobierno Kirchner-Chávez, constituyendo todo un record en la diplomacia bilateral. Más información en sitio web de CEUNM:

http://www.nuevamayoria.com/index.php?option=com content\&task=view\&id=172\&Itemid=30.

12. De acuerdo con declaraciones del ministro de Finanzas venezolano, Nelson Merentes, hacia marzo de 2006 la compra de bonos de la deuda argentina por parte de la República Bolivariana sumaba 2.500 millones de dólares. Ver Radio Nacional de Venezuela, Khttp://www.rnv.gov.ve/noticias/index. php?act $=\mathrm{ST} \& \mathrm{f}=4 \& \mathrm{t}=30416$.

13. Disponible online en: $<$ http://www.sice.oas.org/Trade/mrcsrac/eca_s.asp $>$.

14. Para un estudio detallado del impacto de la liberalización comercial CAN-Mercosur consultar Revista del CEI, $\mathrm{N}^{\circ} 3$ (julio de 2005), pp. 5-23.

15. El Acuerdo incluye además de objetivos comerciales inmediatos, entendimientos en materia de cooperación científico-tecnológica. En este sentido, dicho Convenio establece vinculaciones de organismos de investigación o desarrollo tecnológico de ambos países (INVAP e INTA por la Argentina e INTEVEP e IVIC por Venezuela) para promover el intercambio de profesionales, técnicos, productores para compartir experiencias y fomentar la cooperación y el desarrollo.

16. En este sentido, de acuerdo con el Art. 3 del Convenio, "las Partes recíprocamente prestarán sus servicios y suministrarán las tecnologías y productos que estén a su alcance para apoyar el amplio programa de desarrollo económico y social de ambas Repúblicas. Estos serán definidos cada año según el acuerdo de ambas Partes, en el marco de la Comisión Mixta, precisando las especificaciones, regulaciones y modalidades en que serán entregados". Disponible en línea en http://www.conapri.org download/convenio venarg.pdf.

17. Para más información acerca del programa MERCAL, visitar portal web oficial: http://www mercal.gob.ve/web/index.php?option=com content\&task=view\&id=6\&Itemid=.

18. Según la web del BANDES, encargado de la administración del fideicomiso, "un fideicomiso es una relación jurídica a través de la cual una persona llamada fideicomitente transfiere uno o más bienes a otra persona llamada fiduciario, quien se obliga a utilizarlo en favor de aquél o de un tercero llamado beneficiario". Más información en sitio web oficial del BANDES: http://www.bandes.gob. ve/fid/\#as.

19. Para que un exportador argentino pueda formalizar una venta en el marco de este fideicomiso, se deberá poner en contacto con algún organismo público venezolano (esté o no nombrado en el Convenio de Cooperación) que se encuentre interesado en la adquisición del producto o servicio ofrecido.

Dicha oferta podrá realizarse o bien a través del contacto directo con los entes ejecutores venezolanos, o por intermedio de la representación argentina en Caracas.

Las empresas proveedoras argentinas que logren acordar un contacto de suministro con alguno de los denominados entes ejecutores, para poder suscribir dicho contrato, deben esperar la aprobación 
de los términos y condiciones del contrato de suministros por parte de PDVSA, la cual junto con la Presidencia de la República, selecciona los contratos bajo los parámetros de interés social nacional. Dichos términos y condiciones serán los que negocien entre las partes en cada operación. Pasado ese filtro, PDVSA instruye al Bandes para el pago respectivo.

20. El ministro de Planificación, Julio De Vido, resumió para Le Monde Diplomatique, sus conclusiones de las jornadas en Margarita: "El balance es doblemente trascendente. Primero, porque hubo una gran participación de pymes. Los negocios por 80,4 millones de dólares refieren sobre todo a carnes, vinos, frutas, jugos, textiles, calzado, etc. Son en su mayoría empresas de menor escala, para las cuales una transacción de 200.000 dólares es importantísima. Y por otro lado vemos que el producto de la venta de fuel oil a Argentina, que exigió un egreso de 240 millones de dólares, fue en definitiva utilizado para comprar productos argentinos. El fisco erogó -y el sector industrial, por aumento de precios- pero ese dinero tuvo un retorno a Argentina en trabajo, producción y desarrollo industrial. Esos son los dos principales éxitos de lo ocurrido en Margarita” (Bilbao, 2004: 9).

21. De hecho, la Cámara de Diputados de la Nación, a través de un proyecto de resolución con fecha 8 de julio de 2007, solicitó al Ejecutivo la elaboración de un informe sobre el monto de las importaciones de fuel-oil y gas-oil que se han concretado desde la vigencia del Convenio Integral de Cooperación. Ver detalles en: http://www1.hcdn.gov.ar/proyxml/expediente.asp?fundamentos=si\&numexp=3834 D-2007 (sitio web de la Cámara de Diputados de la Nación).

22. Es importante destacar que Bancoex, solo maneja estadísticas de intenciones de exportación, lo que no garantiza que realmente se haya realizado esta transacción comercial.

23. Recordemos que el Convenio Integral tiene como base principal de los intercambios bilaterales la importación de hidrocarburos venezolanos. Si éstos realmente fueran tan marginales como indican las estadísticas generales, el fondo fiduciario tendría proporciones minúsculas y no se podría explicar el incremento en la intensidad exportadora de los bienes argentinos.

24. De acuerdo al subsecretario de Combustibles, Christian Folgar, en 2004 el Estado tenía previsto importar combustible venezolano por una suma de alrededor de 200 millones de dólares. Sin embargo, de acuerdo con ALADI, ese mismo año solo se importaron 34 millones d la misma moneda. Para mayor información ver: http://www.clarin.com/diario/2004/04/08/p-01601.htm (sitio web del diario nacional Clarín).

25. Acuerdo suscrito el 4 de julio de 2006.

26. Bahamas habría exportado a nuestro país 10 millones de dólares más que Venezuela de acuerdo con datos de ALADI de 2007. Detalles disponibles online en:

http://nt5000.aladi.org/siicomercioEsp/wclSII.ASP?WCI=htmResultadoComercioTotales\&WCE=h pklanillaExcel\&WCU (sitio web de ALADI).

27. En términos relativos, el mercado venezolano representa alrededor del $11 \%$ del comercio bilateral total entre Argentina y su principal socio comercial, Brasil.

\section{Bibliografía}

ALADI (2009), "Sistema de informaciones de comercio exterior (SICOEX)", en: < http://nt5000.aladi. org/siiespanol/>. Visitado el 20 de febrero de 2009. Última actualización: junio de 2008.

J. M. ARAYA y S. COLOMBO (2009), "Una mirada histórica. Modelos de desarrollo, Estado y Sociedad y su incidencia en el surgimiento de las organizaciones públicas no estatales", en prensa.

K. ANDERSON y H. NORHEIM (1994), "From Imperial to Regional Trade Preferences: its Effect on Europe's Intra and Extra-regional Trade", en Review of World Economics, № 129.

L. BILBAO (2004), "Decisivo impulso a la integración regional", en Le Monde Diplomatique, Buenos Aires, $\mathrm{N}^{\mathrm{o}} 62$.

CAN (2009), "Política exterior común: Can-Mercosur", en <http://www.comunidadandina.org/ exterior/can_Mercosur.htm>. Publicado en octubre de 2006 y visitado el 3 de marzo de 2009.

CEI (2005), "Coyuntura comercial. Las exportaciones argentinas frente a la desgravación arancelaria de Colombia, Ecuador y Venezuela", en Revista de Comercio Exterior e Integración, Buenos Aires, $\mathrm{N}^{\mathrm{o}} 3$. 
- (2006), “El ingreso de Venezuela al MERCOSUR", en Revista de Comercio Exterior e Integración, Buenos Aires, $\mathrm{N}^{\circ} 6$.

- (2009), "Panorama comercial argentino N $\mathrm{N}^{\circ}$ 58", Serie de Informes Económicos y Comerciales, Buenos Aires, CEI.

CEP (2007a), "La estructura de destino de las exportaciones argentinas de MOI", Serie de estudios sobre el comercio exterior, en: <http://www.industria.gov.ar/cep/industrial/2007/destinos_moi_2. pdf $>$. Publicado en febrero de 2007 y visitado el 20 de febrero de 2009.

— (2007b), "Las MOI argentinas en América Latina", Serie estudios sobre el comercio exterior, en: $<$ http://www.industria.gov.ar/cep/industrial/2007/Las\%20moi\%20arg\%20en\%20al.pdf $>$ Publicado en noviembre de 2007 y visitado el 21 de febrero de 2009.

(2008), "Crecimiento exportador argentino 2003-2007. Productividad y exportaciones manufactureras", Serie estudios sobre el comercio exterior, en: <http://www.industria.gov.ar/cep/ industrial/2008/s57_crecim_exp_2003_2007.pdf $>$. Publicado en octubre de 2008 y visitado el 19 de febrero de 2009.

CEPAL (2006), Panorama de la inserción internacional de América Latina y el Caribe 2005-2006, Santiago, Naciones Unidas.

CONAPRI (2007), "Convenio Integral de Cooperación entre la República Argentina y la República Bolivariana de Venezuela", en: <http://www.conapri.org/download/convenio_venarg.pdf $>$. Publicado en marzo de 2007 y visitado el 25 de febrero de 2009.

J. M. FANELLI (1999), "Escenarios Económicos”, Módulo 1, en J. M. FANELLI, R. SIDICARO Y L. DEL PRADO, Gestión del Cambio: El desafio de los próximos escenarios, Buenos Aires, Fundación OSDE.

C. GASPAR (2006), "Las exportaciones argentinas frente a la desgravación arancelaria de Colombia, Ecuador y Venezuela”, en Revista CEI, Buenos Aires, №3.

G. GIRADO, G. RODRÍGUEZ DÍEZ y C. GALPERÍN (2006), "Consecuencias para América Latina del nuevo rol de China en la economía internacional: el caso argentino”, en Integración \& Comercio, Buenos Aires, $\mathrm{N}^{\circ} 24$.

INDEC (2009), Comercio exterior argentino 2007, Buenos Aires, INDEC.

B. KOSSACOF (1999), "Las multinacionales argentinas, una nueva ola en los noventa", Documento de trabajo $\mathrm{N}^{\circ} 83$, Buenos Aires, CEPAL.

M. LÓPEZ BELSUÉ (2007), "La gestión Kirchner y los tratados bilaterales", Buenos Aires, en sitio web del Centro de Estudios para una Nueva Mayoría (CEUNM), http://www.nuevamayoria.com/index. hhp?option=com content\&task=view\&id=172\&Itemid=30. Visitado el 27 de febrero de 2009.

D. F. MAZA ZAVALA (2007), Venezuela: economía, tiempo y nación, Caracas, Vadell Hermanos Editores.

OMC (2008), Estadísticas del comercio internacional 2008, Ginebra, Publicaciones de la OMC.

— (2007), Estadísticas del comercio internacional 2007, Ginebra, Publicaciones de la OMC.

- (2006), Estadísticas del comercio internacional 2006, Ginebra, Publicaciones de la OMC.

- (2005), Estadísticas del comercio internacional 2005, Ginebra, Publicaciones de la OMC.

- (2004), Estadísticas del comercio internacional 2004, Ginebra, Publicaciones de la OMC.

OPEP (2009), "OPEC Basket Price”, en sitio web oficial OPEP: http://www.opec.org/home/basket. aspx Visitado el 5 de marzo de 2009.

R. PERINA y R. RUSSELL (1988), Argentina en el mundo (1973-1987), Buenos Aires, Grupo Editor Latinoamericano.

F. PIOLI (2006), "El ingreso de Venezuela al MERCOSUR", en Revista del CEI, Buenos Aires, № 6 . (2007), "Estrategias de Integración Comercial en el hemisferio: el ALCA y la ALADI como opciones de política para la Argentina", en Serie de Estudios del CEI, Buenos Aires, Año 5, № 11.

N. PONTIROLI y B. FALCÓN (2007), "Incorporación de Venezuela al MERCOSUR. Análisis de factibilidad para el incremento de las exportaciones", en Informe Exportar N N 29, Buenos Aires, Fundación Exportar.

J. SEVARES (2007), “Cooperación Sur-Sur o dependencia a la vieja usanza? América Latina en el comercio internacional”, en Nueva Sociedad, Buenos Aires, № 207. 
SICE (2006), "Tratado de Libre Comercio Colombia, Ecuador, Venezuela y MERCOSUR (ACE $\mathrm{N}^{\circ}$ 59)", OEA Trade Agreements in Force en: <http://www.sice.oas.org/Trade/mrcsrac/eca_s.asp>. Publicado en febrero de 2006 y visitado el 24 de febrero de 2009.

L. VINOGRADOFF (1997), "Los argentinos también bailan salsa y toman ron”, Buenos Aires, Diario Clarín.

UNCTAD (2006), Informe sobre el comercio y el desarrollo 2006, Ginebra, Naciones Unidas.

Enviado: 13/04/2009. Aceptado: 19/04/2010 